\section{Measuring the willingness of dive tourists to pay fishers not to fish in a no-take zone}

Ecosystems provide an array of direct and indirect services to human populations. In tropical marine areas, such ecosystem services often include food provision (i.e., fishing) and ecotourism (i.e., diving). In cases where there are conflicts between these services such as where fishers want to fish but divers want to see abundant, biodiverse ecosystems - examining the economics of various alternative policy solutions may be useful.

The various ecosystem services provided by tropical marine areas worldwide such as food provision through fishing, or ecotourism opportunities through diving - are under increasing use in general. Sometimes such uses are unsustainable or conflict with one another. One way to help ensure the continued provision of ecosystem services is through establishment of marine protected areas (MPAs), where uses are ideally planned and managed with sustainability in mind.

More than $300 \mathrm{~km}$ off the coast of Brazil is the small archipelago of Fernando de Noronha. Around this archipelago is a $26-\mathrm{km}^{2} \mathrm{MPA}$, divided into two zones. One zone, which encompasses $70 \%$ of the park, is no-take: fishing is banned but diving is allowed. The other zone is multi-use, allowing fishing as well as diving.

Traditionally the small population of Fernando de Noronha - fewer than 3000 residents has relied on fishing for its food and economy, with tuna fishing (by handline) most common now. However, diving by tourists has boomed in recent years, particularly to see sharks, which use the inshore waters as an important nursery. With 24,000 divers visiting annually, Fernando de Noronha has become a premier shark tourism destination.

A conflict has arisen between these uses. For eight months of the year, fishers use the multi-use zone to catch sardines, which they use as bait to catch tuna in pelagic waters outside the MPA. But for the remaining four months, the waters of the multi-use zone become rough and unsafe, while the waters of the no-take zone remain calm. When the MPA was designed in 1988, it was understood that local fishers would fish in the notake zone when necessary. But federal legislation in 2000 toughened the no-take zone's rules. Fishers who disagree with the no-take zone have been very vocal in protesting the toughened rules. Meanwhile park managers have stated any fishing in the no-take zone could impact the tourism experience by catching sardines the sharks eat and by disturbing juvenile and mating sharks.

This study applied an economic analysis to the user conflict. The analysis focused on two aspects: 1) estimating how much revenue the local fishers would lose if the no-take zone were strictly enforced year-round, and 2) gauging whether tourists would be willing to pay the fishers not to fish in the no-take zone. The authors calculated that if visitors paid an additional BRL 1.20 (USD 0.60) as a daily fee, it would add up to enough to balance the lost annual revenue of the fishers. (At the time of the study in 2016, the MPA's daily entrance fee to the no-take zone was BRL 89 [USD 53] for Brazilians and BRL 178 [USD 107] for foreigners. So the proposed additional fee would be relatively minimal.)

A total of 579 tourists were interviewed. The finding: Most tourists (67-71\%) would accept
This is a summary of: Paying the price to solve fisheries conflicts in Brazil's Marine Protected Areas

Accessible at: https://marxiv.org/45k96

Authors: Priscila Lopes, Sebastian Villasante

Added to MarXiv:

April 2018

Published: Marine Policy, 2018

Suggested Citation: Measuring the willingness of dive tourists to pay fishers not to fish in a no-take zone. OCTO (2018). DOI: 10.17605/OSF.IO/98FU5

See more MarXiv summaries at https://www.marxivinfo.org/ summaries

Share your research in MarXiv and the MarXiv Team may summarize it, just like this!

Step-by-step instructions on how to share your research in MarXiv are detailed at https://www.marxivinfo.org/ submission

Across all disciplines, papers available for free with a preprint (also known as "Green OA") are cited $30 \%$ more than the world average (DOI: $10.7287 /$ peerj. preprints.3119v1) 


\section{MarXiv Summary}

MarXiv: The free research repository for the ocean \& marine-climate sciences

paying more if the extra money were given to fishers. Such an alternative was generally perceived as a win-win solution, as it would encompass maintaining fisher income, shark status, and the current economic gains of tourism. (The study breaks down the findings according to a number of criteria, including whether the respondents had seen sharks on their visit yet.) Notably, Brazil already has a Payment for Ecosystem Services system, varying from state to state, that compensates fishers during closed seasons to support the reproductive period of some species.

The authors conclude that future MPAs should outline clear compensatory mechanisms to support the transition from a resource-consumptive economy to less-consumptive alternatives for those directly affected by conservation.

The MarXiv Team

Nick Wehner,

Director of Open Initiatives, OCTO

Raye Evrard,

Project Manager, ОСТO

Allie Brown,

Project Associate, ОСТO

Sarah Carr,

Chief Knowledge Broker,

ОСTO

John Davis,

President, OCTO

Correspondence

Nick Wehner

nick@octogroup.org

Financial support for MarXiv comes from the David and Lucile Packard Foundation.

The views expressed herein are those of the MarXiv Team and should not be interpreted as representing the opinions or policies of the Packard Foundation or other funders of MarXiv.

Join the MarXiv Summaries monthly newsletter at https:// oct.to/marxivsum

MarXiv is an OCTO Initiative
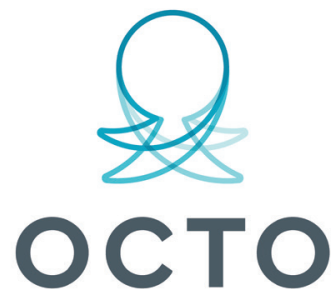

OPEN COMMUNICATIONS FOR THE OCEAN 